\title{
Job Satisfaction Indicators and Their Correlates
}

\author{
STANLEY E. SEASHORE \\ THOMAS D. TABER \\ University of Michigan
}

Conceptions of job satisfaction until very recently have been largely psychological and individualistic in orientation. Empirical studies have been confined to local situations or special populations with interpretive purposes reflecting the values of employed individuals or of their managers. However, if job satisfaction measures are to be useful in monitoring the quality of employment on a societal scale, it will be necessary to enlarge the perspective, to invoke some societal and political values, and to begin to treat job satisfaction in the context of a larger array of associated variables.

The measurement of job satisfaction as a social indicator may have three roles: (1) to represent a valued product of society-a component of the psychological GNP; (2) to provide a monitoring and diagnostic aid for early warning of societal dislocations, policy or program failure, and slowly developing societal changes; and (3) to provide a significant component in the theories and models to be used in the formulation of social policy and programs. Opinions differ on how prominent and (C) 1975 Sage Publications, Inc. 
how effective job satisfaction measures will be in these three roles.

The utility of job satisfaction measures rests on the development of multiple measurement methods that are standardized, suitable for wide use, and capable of detecting population differences and population changes. In addition, the utility rests upon these measures having an agreed conceptual and "real world" reference as well as a known matrix of causal and consequential relationships to other significant variables. Both requirements must be met before convincing proof can be advanced as to the practical utility of job satisfaction measures for anticipating, understanding, and influencing future outcomes of present societal conditions.

These themes provide the structure for this paper. In the next section, we give an overview of the state of the art in the measurement of job satisfaction. The section following that provides an approach to organizing, or modeling, the correlates of job satisfaction. The final section suggests some priorities for further research and development.

\section{JOB SATISFACTION INDICATORS}

This section summarizes considerations that bear upon the choice of approaches and operational methods for measuring job satisfaction. We shall limit the discussion to approaches that rest upon direct inquiry through interview or questionnaire methods to produce data that can be aggregated to provide job satisfaction indicators for variously defined populations. We exclude from discussion: (1) indirect approaches that draw inferences about job satisfaction from presumed causal or consequential phenomena; (2) approaches that are primarily individualistic and diagnostic and, therefore, not usually applicable for generating population indicators; and (3) approaches that have utility primarily for empirical and theoretical discovery rather than for population description purposes.

We first review the commonly used forms of primary data, then some commonly used derivative job satisfaction indi- 
cators. A scheme is presented to guide the evaluation of these several indicators. These are applied to draw implications for preferred future methods.

Throughout the paper, except where noted, we will use the term "job satisfaction" inclusively to refer also to dissatisfaction without intended prejudice whether satisfaction and dissatisfaction are best treated as polar opposites or as two conceptually different variables.

\section{PRIMARY DATA}

By primary data we mean the "raw" responses given by individual respondents to verbal questions or comparable stimuli. There appears to be a fixed roster of basic forms of primary data, even though innumerable variations on these are known. Two kinds of primary data are distinguished: facet-free and facet-specific.

Facet-free primary data are obtained when the respondent is asked to indicate his global satisfaction with his job and job environment without specifying in advance the facets to be considered or how they are to be combined. In effect, each respondent provides a net response derived from his own set of facets, weighted or otherwise combined in his own unique fashion, with unstated and unique assumptions not only about the context for evaluation, but also about his own "fit" to the job and its environment, and with the environmental "reality" defined by his own perceptions and cognitions. Normative, cognitive, and unconscious elements in the evaluation are invited. The stimulus questions are usually phrased (or nonverbally displayed) with an intent to impose the fewest possible constraints upon his perceptual, cognitive, and evaluative processes. Several complementary stimuli may be used to diversify the unavoidable constraints.

Facet-specific primary data are obtained when the respondent is asked to represent his satisfaction with respect to some specified facet of his job or job environment. Since the facet specification is never exhaustive or definitive, the difference 
between a facet-free and a facet-specific inquiry is only one of degree. For example, the query "How satisfied are you with your pay?" elicits a net response that includes consideration of unspecified subfacets (amount of pay, certainty of pay, rate of increase, adequacy to need, and so forth), unspecified "reality" (last week's pay, pay after deductions, pay confidently expected next year, and the like), and unknown perceptual, cognitive, and evaluative processes. Nevertheless, facet-specific methods allow the inquirer some control over the range of facets to be included in his data, an added degree of comparability among different respondents, and closer and more confident linkage between the response obtained and the "reality" of the job environment or of the person under investigation. Facet-specific queries, thus, vary in their specificity. In addition, they take the following forms:

(a) direct report of degree of satisfaction with facet (satisfaction);

(b) amount or degree of facet provided by job (is now);

(c) amount or degree of facet respondent would like to have (would like);

(d) amount or degree of facet respondent should be provided (should be);

(e) importance of facet to respondent (importance).

The forms of response exist in great variety, including simple check-list or "yes-no" responses, rank ordering, scalar responses (e.g., Likert scales, "faces," and the like), and the more complex forms such as "self-anchoring" scales. While these alternatives invite useful discussion about their relative reliability, efficiency, simplicity, item utility, and conceptual assumptions, such issues will not be raised here. Each alternative provides primary data permitting aggregation for population comparison or social indicator purposes.

\section{DERIVED DATA}

In the case of primary data that represent the direct or implied expression of job satisfaction, social indicators may be 
derived by a simple aggregation of primary data for individuals and then an aggregation of individual data for the population. This is often done, for example, with respect to multi-item, facet-free primary data, and with primary data of types a and $b$ above. However, more complex forms of derivative indexes are commonly preferred for various reasons. Procedures for deriving indexes from primary data include: (1) differential weighting of items; (2) clustering of items into factors or dimensions on conceptual or empirical grounds; (3) converting primary data to derived discrepancy scores on theoretical, conceptual, or empirical grounds before aggregation; (4) retaining individual facet item data for differential uses in interpretation or analysis; (5) removing some uncontrolled response variance before aggregation; and (6) adjusting primary data for known or presumed bias before aggregation. Any of these procedures may be employed singly or in combination with others. The last three procedures are relatively trivial or at least noncontroversial at the present time; the first three are topics of current inquiry and dispute.

Weighting of item responses (or of derived factor scores) is based upon the differential importance of the facets, with importance determined either by the respondent's own report of importance, on theoretical or empirical importance estimated for classes or respondents, or upon empirically derived weights that maximize the correlation between the resulting social indicator and some external criterion of interest. While the logic of weighting is impeccable and the operations are relatively simple, there is an emerging consensus that differential item weighting seldom offers a significant gain in construct validity, measurement reliability, or predictive power. Plausible reasons for this result are discussed by Ghiselli and Brown (1955), Ewen (1967), and Quinn and Mangione (1973), and include: (1) the "weighting" of facets in job satisfaction indexes has already been incorporated efficiently, perhaps unconsciously, by the individual in giving his responses to either descriptive or evaluative queries about his job, so that further weighting introduces little other than error; and (2) even powerful weights 
have little influence upon summative indexes when, as is usually the case, the component facets are numerous and the facet responses are positively correlated.

The hierarchical organization of facet primary data into factors, dimensions, or subindexes may be on either rational or empirical grounds. The former reflects the designer's intentions or interpretations with respect to the meaning of facet items, and the latter reflects the empirical statistical clustering or factorial weights of the items. The preservation of subindexes is useful for some social indicator purposes because the subindexes generate interpretations and predictions that are somewhat different, or at least of differential power, for the several subindexes. This is notably true for simple two-factor subindexes such as those differentiating intrinsic and extrinsic job satisfaction, or hygiene and motivator factors.

The optimum dimensioning of job satisfaction remains an unresolved matter, although considerable consensus has emerged from those empirical analyses using relatively large and diverse populations (Cobb and Quinn, 1973). Nonrepresentative populations and nonrepresentative sets of facet items result in divergent or even unique factorial structures (Ronan and Marks, 1973). Ronan (1970) may be correct in his view that demographically, organizationally, or occupationally different populations have significantly dissimilar factorial structures with respect to facet job satisfaction. If so, social indicators based upon subindexes will have diminished value for describing nonhomogeneous populations while at the same time having enhanced value for diagnostic and differential prediction purposes with special populations. Although factor structures may vary among populations and situations, a relatively small group of factors can nonetheless account for a preponderance of the variance in most reported factor matrices. A basic problem lies in the absence, so far, of any plausible inclusive definition of the domain of relevant facets to be sampled or represented in job satisfaction measuring instruments.

Discrepancy scores derive measures of facet satisfaction by subtracting the reported degree of facet fulfillment ("is now") 
from the individual's report of how much of (facet) he would like to have ("would like"), or how much he thinks there should be ("should be"), or his rating of its importance. The logic of discrepancy scoring rests on a conception that satisfaction is a result of fit between need and need fulfillment, between fulfillment and one's estimate of the amount that would be equitable, or fit between the relative degree of fulfillment across a set of facets and the relative importance of these facets. While discrepancy scores have some conceptual elegance and provide a desirable linkage to psychological theory, there is little evidence that the resulting derived facet satisfaction measures are empirically more valid or more reliable than more direct estimates. Arguments against the use of discrepancy scores include: (1) the units of measurement of derived scores (i.e., equivalence of scale intervals and "objective" reference of scale points) are ambiguous and make the scores less meaningful for descriptive purposes; (2) the errors of measurement and two bias components may be additive rather than randomly off-setting; and (3) the respondent's experience of discrepancy may be incorporated in his perception and report of degree of fulfillment ("is now") with the effect that the calculation of discrepancies is similar in its effect to differential weighting of doubtful effectiveness. The arguments favoring discrepancy scoring, other than its conceptual elegance, are largely empirical: derived facet scores have been known to "work" as representations of satisfaction in hypothesis testing and predictive schemes (Porter and Lawler, 1968 and Locke, $1969)$ and occasionally are found to work better than nondiscrepancy scores (Wanous and Lawler, 1972).

\section{OPERATIONS AND THEORETICAL CONSTRUCTS}

For social indicators, measures should ideally be relatively direct operational translations of core theoretical constructs. In addition, it is highly desirable that they be definable in unambiguous language and measurable in some metric that allows ready inference about or prediction to observable 
physical events or behavioral changes. Current measures of job satisfaction are all somewhat deficient on one or another of these desiderata. These operational deficiencies probably derive from the complex nature of job satisfaction as a theoretical construct. Prevailing conceptions view job satisfaction as a joint product of the characteristics of the job and job environment, on the one hand, and the characteristics of the person on the other, with the effective set of relevant job characteristics and personal characteristics depending upon unspecified combinations and interactions among them. In addition, both the person and the objective environment are represented in the causal scheme through conscious and unconscious processes that involve perceptual selection and distortion as well as choices of relevent comparisons that are subject to variation and change. In short, the conception of causes leading to or maintaining job satisfaction is very complex, with an open-ended roster of causes and moderating variables and with a high potential for abrupt and significant changes over time in an individual case. The instability arises because the job-person interactions allow powerful consequences from small changes in single variables. Moreover, quantum changes (as compared to gradual changes) may occur as variables and sets of variables are deleted or activated in the effective set of then-relevant causal variables.

A possible and not uncommon reaction to such an image of fluid complexity is to conclude that measures of job satisfaction for populations "do not mean anything"-i.e., they have little connection with the realities of behavior and the objective conditions of the real world except in the individual case, and that, therefore, the outlook for population regularities useful for social indicators is dim. Schwartz, Ronan, and Day (1974) take the rather extreme position that job satisfaction is hardly worth measuring except for individuals or for highly homogeneous sets of persons, despite its compelling prominence as an aspect of personal life experience. Others attempt to reduce the complexity by avoiding reliance upon direct satisfaction responses in favor of deriving satisfaction scores from combinations of variables which figure earlier in a presumed causal 
network. Such efforts, as noted earlier, have been illuminating but not notably successful in producing a single optimum measurement strategy. Still others take the more optimistic view that the "fault" in job satisfaction measures lies not in complexity of determination, nor in absence of close correspondence between some category of causes (e.g., "objective" environment) and resultant job satisfaction, but rather the fault lies in our naive expectation that job satisfaction should be understood in simplistic and universalistic terms of economic and psychic rationality.

In our view, the foregoing "faults" of job satisfaction measures as social indicators turn out to have some advantages. Direct measures of job satisfaction, whether in facet form or facet free, contain sufficient reference to "objective" work environmental factors to sustain useful inquiries into prevailing criteria for optimizing work environments. They also contain sufficient representation of expectations, needs, aspirations, and work-related values to allow motivational interpretations-i.e., indications of who might change their future behavior and in what ways. They are sufficiently "unstable" to be relatively sensitive indicators of change in expectations, needs, and aspirations in specific subpopulations defined by occupational, demographic, or organizational membership characteristics. What more could one ask of a social indicator? One could ask that these three components be separately measurable, but this is not likely to be easily accomplished if they are indeed dynamically merged in the experience of satisfaction. One could also ask for more in the way of mapping causal and consequential correlates of job satisfaction (the subject of the next section of this paper), so that socially significant interpretations may be advanced for study or action.

\section{EVALUATING ALTERNATIVE MEASURES OF JOB SATISFACTION}

There is no obviously preferred, single conceptual base or operational strategy for measuring job satisfaction in the context of social indicators. Instead, given multiple purposes of 
indicators and varied operational constraints, the choice rests on trade-offs among competing and sometimes incompatible considerations. We suggest the following rather obvious considerations:

(1) cost-efficiency (The range is from single-item direct satisfaction questions to multiple-item, dimensionalized, discrepancy-scored, weighted, and adjusted instruments.);

(2) conceptual-theoretical base (The variation includes emphasis on causes versus consequences of satisfaction, on individualistic versus population emphasis in interpretation, on transient versus stable components, and so forth.);

(3) reliability, measurement error;

(4) individualized versus generalized component weights (if weights are used);

(5) availability of standard items and component dimensions for descriptive and analytic uses;

(6) face validity of items and indexes-for communication, interpretation;

(7) known norms and statistical properties;

(8) vulnerability to scoring and data collection errors;

(9) transparency to respondent, risk of social desirability bias, feasibility of purposeful distortion;

(10) scope of applicability-i.e., range of persons and jobs for which a measure is usable.

For national survey purposes, considering the relatively primitive state of the art, one can propose that the best strategy keeps the maximum number of indicator options open while at the same time optimizes the comparability and additive properties of surveys conducted by different people over some span of time. Such optimizing might best be realized by adopting for general use a nested set of instruments and procedures. Its components should be usable separately or jointly with optional additions designed to enlarge the utility of the set when special purposes (e.g., theoretical, predictive 
explorations) are to be emphasized or permitted, and with available normative data for all components and their degree of comparability. Such a nested set of instruments could include:

(1) A facet-free direct job satisfaction instrument usable either in the form of its single best item or multiple-item additive and unweighted index.

(2) A scalar-response, multiple-item, facet-oriented, direct satisfaction instrument designed to be equivalently usable in interview or questionnaire form, with core facets representing some agreed and empirically derived set of factorial components derived from a replicable sample of the national employed populations, and with both short and long forms and norms.

(3) A scalar-response supplemental instrument designed to match the items in 2 and with optional use for obtaining any or all of the data forms potentially needed for deriving weighted or discrepancyscore versions of job satisfaction.

(4) Provisions for experimental facet items additional to 2 and 3 above so that alternative factorial components may be employed as needed, and newly emerging or newly discovered significant facets may be introduced (this specification is to avoid premature rigidity, and to allow statistical transformation from new to old versions of the instrument).

Such a nested set of instruments would permit substantial flexibility in several respects while still maintaining a core set of indicators for normative and comparative purposes. Field cost or other constraints could be met by using single items or short forms; criterion-optimizing analytic procedures and theoretical models could be accommodated similarly; any desired degree of reliability could be obtained in a particular application up to the limit imposed by the inherent unreliability of respondents; the possibility for comparability and equivalence conversions among different indicators would be optimized. Referring to the above ten suggested criteria such a strategy could maximize criteria $3,5,6,7$, and 8 , could impose some constraints as to criteria $1,2,4$, and 10 , and would probably have to accept the defect of criterion 9 , i.e., transparency. 


\section{SOME CONCLUDING REMARKS}

It is worth noting that no instrument exists for job satisfaction measurement that has, as yet, all of the properties and points of flexibility we assert to be achievable and desirable. Several, such as the Job Description Index (Smith et al., 1965), JobSat '73 (Quinn and Shepard, 1974: 50-69) and the SRA Attitude Survey (Science Research Associates, 1973), approach that target in different ways. The job satisfaction indicators produced by the several instruments and from different conceptual bases notably are not comparable. This noncomparability stems in part from relatively simple discrepancies among measures of job satisfaction with regard to the number of response categories that are provided (some use a four-point, others a seven-point scale) and the type of arithmetic used to construct the satisfaction score (some index rules reach an overall score by adding, others by multiplying, individual item scores). More importantly, when we find, as did Wanous and Lawler (1972) in their multitrait-multimethod matrix analysis of job satisfaction measures, that different kinds of job satisfaction exist, then we can expect that different and noncomparable measures will have validity. Thus, we anticipate some data discrepancies in the next section when we treat the correlations of (variously measured) job satisfaction with classes of potential causal and consequential variables.

Finally, we remind the reader that our treatment of the measurement of job satisfaction has been limited to those procedures that appear to be readily adapted to large-scale social indicator applications, thus omitting reference to some measurement approaches that have promise or advantages in other contexts. Examples are: forced-choice and rank-ordering response formats; indirect and nontransparent measurement; inference to job satisfaction from behavioral observation; assessment of "deep" dimensions of job satisfaction through projective, semantic differential, and related techniques; use of individual moderator variables to segregate respondents who can be described as indifferent, ambivalent, or holders of "nonatti- 
tudes" regarding their jobs (Dubin, 1970), and error-choice methods.

\section{CORRELATES OF JOB SATISFACTION}

This section reviews what is known and what should become known with respect to the correlates of job satisfaction. The range of known correlatives is displayed in a way that will aid the assessment of the potential role of job satisfaction as one indicator, among others, of the quality of employment. Some examples of reported empirical correlations will be given for illustrative purposes, but we do not attempt to review and catalog all published reports bearing on the matter, nor to provide evaluation of the various empirical generalizations that have been advanced. We shall ignore for the present the diversity of concept and measurement of job satisfaction treated in the preceding section.

\section{SOCIAL INDICATORS AND INTERPRETATIVE MODELS}

The meaning of any social indicator is found in its assigned role in some conception of how the society "works." Thus, a measured change in some indicator-infant mortality rate, for example-is uninterpretable apart from some known or assumed dynamic structure of sequential changes that relates the observed change to causes, consequences, and moderating conceptual factors. Ideally, one should have an empirically validated theory, broad in scope, embracing multiple causes and consequences, capable of accommodating additional variables (i.e., an open system), and one that treats changes over time (i.e., a dynamic theory). Such an interpretive model would permit the evaluation of a change in some social indicator in several useful ways, most importantly in estimating future implications of the observed change and in identifying possible societal actions to forestall or counteract undesirable consequences. 
With respect to job satisfaction, there does not exist any such comprehensive theoretical model. However, there are micromodels treating limited segments of such a more comprehensive model, and there are known empirical correlations that help to identify classes of variables that must be taken into account and which can guide future work into profitable directions.

One example of such a micro-model specifies that more challenging jobs (i.e., those with more autonomy, allowing greater use of valued skills, and so on) are associated with higher job satisfaction. In a dynamic form with causal specification, it is asserted that "enrichment" with respect to the degree of challenge leads to an increase in job satisfaction. There is ample correlational and experimental evidence that such an association can exist and can be quite strong (Lawler, 1969; W. E. Upjohn Institute for Employment Research, 1973: 188-201); but rather little is known about the contextual conditions within which the association holds (Hulin and Blood, 1968) and about variables that moderate the strength of the association. The generalization stands as a valid and useful one even though parts of the relevant correlational matrix remain unexplored.

Other available micro-models treat job satisfaction in a causal rather than a consequential role. An example is the formulation that occupations that are relatively high in extrinsic job satisfaction will induce relatively high rates of premature death from chronic heart diseases, while occupations relatively high in intrinsic job satisfaction will induce lower death rates. This proposition has been supported in only two correlational tests but with impressively large correlation coefficients (House, 1972). Two points are illustrated by this example: (1) job satisfaction cannot in all circumstances be treated as a unidimensional construct; and (2) relationships that are trivial and unreliable at the individual level may be highly significant and interpretable when aggregated-in this case, aggregated to the occupational level.

Figure 1 shows the main components of our map of the correlates of job satisfaction. To the top and left are shown rectangles representing classes of variables thought to be 


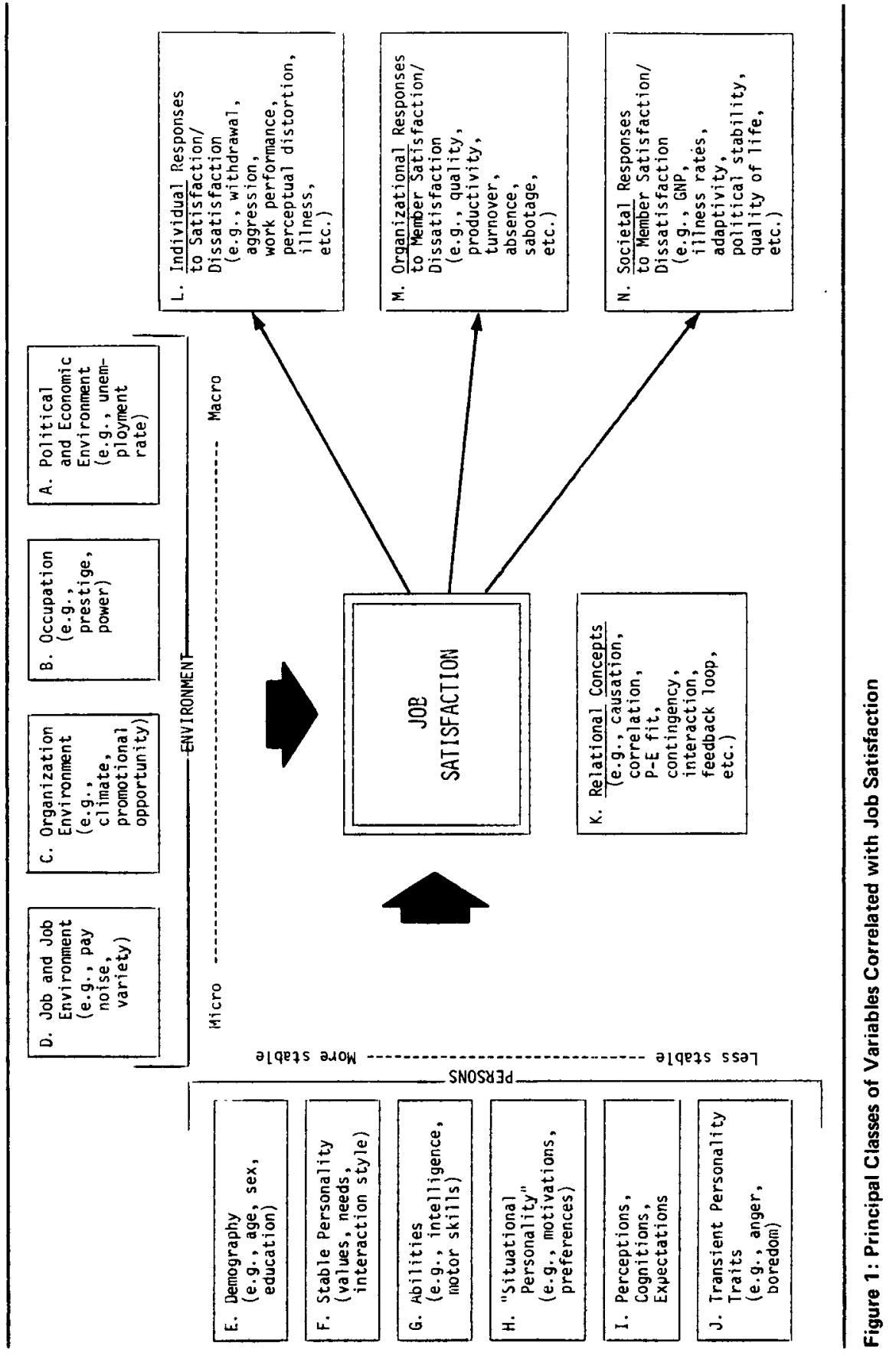


primarily causal in relation to job satisfaction. Environmental descriptors are distinguished from person descriptors, and these in turn are ordered, respectively, from macro-environment to micro-environment, and from relatively stable attributes of the person to those less stable. On the right are three classes of valued consequents associated with job satisfaction, differentiating those that are primarily interpretable at the organizational or societal levels. In the lower center appears a reminder that several different relational concepts are to be employed in the relational domain. The arrows shown merely indicate the probable or dominant causal direction of relationships; not represented at all are the interactions, feedback loops, and so on, which we presume to be present in confusing number.

The reader should not look to this figure for more meaning than is intended. Note that: (1) the categories of variables are somewhat arbitrary; (2) the categories are not mutually exclusive, for the assignments of some variables depend upon their analytical uses as much as upon their inherent conceptual nature; and (3) some of the suggested correlates of job satisfaction are firmly established through both plausible theory and empirical data while others are speculative and possibly controversial.

\section{ANTECEDENTS OF JOB SATISFACTION}

Figure 1 portrays the principal relationships between job satisfaction and antecedent variables identified through empirical research. One basic characteristic of the figure is its portrayal of job satisfaction as a function of a continuum of environmental characteristics ranging from the macro political/economic environment to the specific characteristics of the individual job. Satisfaction is also pictured to be a function of characteristics of the individuals who occupy jobs ranging from relatively stable attributes and states to more transient states such as anger, anxiety, and boredom. In addition, job satisfaction is shown to be a joint function of complex interactions among these two broad classes of variables. The figure implies that changes in the structure of cause-and-effect relationships 
might occur from changes in either the environment or the individual and that the structure of antecedents to satisfaction might be quite different in cultures where the institutions and/or prevailing values are quite different from our own. The structure might also be quite different even in the short-term future of our own society as we evolve organizations with structures and processes quite different from those existing today and as change occurs in the abilities, expectations, and aspirations of the populace.

\section{MACRO-ENVIRONMENTAL FACTORS}

Although relatively little programmatic inquiry has been made into the role of economic, political, cultural, and similar broad factors as they affect job satisfaction, evidence suggests that this class of variables is indeed relevant to job satisfaction. For example, Hulin and Blood (1968) and also Kendall (1963) found that characteristics of the communities in which workers reside need to be taken into account to understand job satisfaction. Form (1973), comparing auto assembly plant workers in four countries, shows that there are differences in work-related values, motives, and satisfactions associated with degree of industrialization, while other relational regularities appear to be impervious to culture and context. There are speculations, but no adequate evidence, that fluctuations in unemployment rate and general public optimism about future economic conditions impact on job satisfaction.

\section{OCCUPATIONAL CHARACTERISTICS}

That job satisfaction is related to general characteristics of occupations (not to be confused with properties of jobs) and the occupational structure has been consistently demonstrated from the earliest comparative study of Hoppock (1935) to the more recent studies such as those of Quinn et al. (1973). Numerous studies show significant relationships between job satisfaction and such properties of occupations as status, 
prestige, power, and control, among others. However, because of defects in study design, not much is known about the degree to which the various occupational characteristics contribute independently to job satisfaction.

\section{ORGANIZATIONAL ENVIRONMENT}

This domain of causal variables is extensively represented in the theoretical and empirical literature. Variables which have shown evidence as significant organizational antecedents to job satisfaction include structural variables such as size and "shape" (e.g., Carzo and Yanouzas, 1969), complexity, centralization, and formalization (e.g., George and Bishop, 1971); process variables such as prevailing decision-making and conflict management styles, team collaboration and role conflict; and such encompassing variables as "organizational climate" (Litwin and Stringer, 1968).

\section{THE JOB AND JOB ENVIRONMENT}

By far the major part of the job satisfaction research has been concerned with the proposition that an individual's job satisfaction is in substantial part a direct product of the objective characteristics of his job and its immediately relevant environment. Many hundreds of reports assert or imply such a proposition and present empirical data bearing upon it. These data are diverse in quality and scope and offer a somewhat bewildering array of correlations and choice of job characteristics for treatment, but they without doubt confirm the general proposition. Smith et al. (1969) report that in a number of replications in different settings, the amount of pay associated with a job correlates positively with degree of job satisfaction. No one is surprised at this, although some are surprised at the rather low magnitude of the correlations-perhaps about .20 for the employed population as a whole.

Many inquiries assume that the characteristics of jobs as perceived by the occupants may be substituted for "objective" 
characteristics or, in a stronger form, that the perceptions of job characteristics are indeed the causal reality. It is generally true that the correlations are stronger when based upon perceptions than when based upon independently and more objectively measured job characteristics even when this increment cannot be attributed to contamination by similarity or simultaneity of measurement methods (Quinn et al., 1973).

It is further established that the correlations between job characteristics and job satisfaction are highly interdependent with demographic, occupational, and personality factors in such a way that any underlying population relational constancy is likely to be well hidden or exaggerated by the presence of such uncontrolled variance. The promotional potential of a job is insignificantly correlated to job satisfaction among older workers, for example.

Most past inquiry has aimed at locating and defining the job characteristics that are the more universal or more potent sources of job satisfaction. The resulting lists of relevant descriptors tend to be rather long, as well as open ended: additions arise from reconceptualization of variables and from extension of inquiries to new populations and job situations.

The processes that link job characteristics to job satisfaction are not very well understood, but almost certainly they involve something more than a simple additive effect of discrete, independent characteristics. Configurative and multiplicative models and contingency models, for example, are certainly applicable and will improve our understanding of job satisfaction as a direct response to job characteristics. Nevertheless, as noted earlier, even simple models have great power of explanation in this region of our map. It is known that a rather short, selected roster of job descriptors treated additively, and using a mixture of "objective" and "perception" descriptors, correlates about .74 with job satisfaction for a probability sample of employed people (Quinn et al., 1973). Even if methodological bias and perceptual distortions have inflated this result, the remaining relationship offers considerable guidance to the interpretation of job satisfaction and to programs for inducing it. 
The explanatory power and simple clarity gained from treating job characteristics as a cause of job satisfaction is further enhanced by the substantial agreement existing among researchers with respect to the subjective categories that people use when describing or evaluating jobs. Factorial analyses-more than fifty of them in the last few years-agree in the finding that much of the total variance in job descriptors can be accommodated in a small number of underlying dimensions or variable clusters. Recent summaries of this work (Landy, 1973; Ronan and Marks, 1973) suggest that perhaps five or seven factors will serve for most applications. Two important caveats must be added, however: (1) not all five, or seven, general factors appear in all data sets; factors unique to a given organizational setting or subpopulation appear in all data sets and may sometimes outweigh the more global factors in their relational power to job satisfaction; and (2) existing factorial and clustering methods ignore or override plausible ideas concerning the patterning or interactions among any array of specific job descriptors.

The conclusion remains that the causes of job satisfaction lie substantially, although far from exclusively, in the immediate realities of jobs and job environments, and they lie even more strongly in the perceptions of these realities. Even with the limited knowledge now at hand, useful diagnoses of the causes of changes in job satisfaction are feasible. Further, it is feasible to develop general models to guide the optimization of the satisfying properties of jobs and job environments, as is illustrated by the propositions of Emery and Trist (1965) based on a combination of theory and empirical information (described in Hill, 1973), or by the wholly empirical model of Quinn et al. (1973).

\section{PERSONAL CHARACTERISTICS}

Figure 1 shows that job satisfaction is affected by the personal characteristics of individual workers, and that the relevant personal characteristics range from relatively enduring 
characteristics, on the one hand, to others that are relatively fleeting, transient, although perhaps recurrent states. Because of the existence of relatively enduring personal and individualistic characteristics, we can expect that some persons, quite independently of the environments they encounter, may experience and report satisfaction quite differently from others in nearly identical environments. We expect that such instances are rare and also uninteresting for understanding the quality of employment. The existence of less stable personal characteristics, and particularly those that are induced or modified by nonjob environmental changes, suggests that the same individual will be more satisfied at one time than another, even if his job environment were to remain constant. It is unlikely that a useful social indicator would be sensitive to transient fluctuations in personal characteristics, nor is it necessarily desirable that it should be. On the other hand, it is essential that a social indicator be sensitive to the existence of identifiable, large categories of employed people who experience job satisfaction in distinctive ways and in response to distinctive environmental influences, as compared with the general population norms.

\section{DEMOGRAPHY}

Much of the job satisfaction research and literature is restricted to those personal characteristics that are inherent in historical and biographical information-e.g., sex, age, educational achievement, job tenure, region of residence, father's occupational level, and the like. When used as surrogates for personality characteristics, such variables are inexact, loaded with unknown and unwanted variance, and unusable in most psychological and sociological theoretical models. They are extremely difficult variables to interpret yet they are the most frequently used (and misused). At the same time, it is essential to take them into account for they are the basis for much of the selective, nonrandom clustering of like people in like jobs and job environments. Comparisons of the satisfaction correlates of environmental conditions can hardly be undertaken without 
either experimental controls or else some statistical control through demographic data. To take a more positive view, it should also be noted that societal programs (e.g., legislation) responsive to social indicators usually require demographic definitions of their purposes, as in the case of anti-discrimination, public vocational training, and child labor legislation.

Some demographic correlates of job satisfaction are substantially known. Job satisfaction, for example, is correlated with age (older are more satisfied), with sex (but only in interaction with other demographic variables), with educational achievement (those with more than high school achievement are more satisfied). Such correlations are, for the most part, weak for large and diverse populations but often strong in interaction with other variables for particular populations based on organizational or occupational membership.

\section{PERSONALITY CHARACTERISTICS}

Directly measured enduring personality characteristics have only rarely been employed in studies of job satisfaction. No generalizations seem safe at this time, although there are enough significant findings reported to indicate that such characteristics are relevant to the understanding of job satisfaction. The significant associations are not generally found in a direct, ceteris paribus, causal linkage but rather in interaction with job, occupation, and environmental variables. For example, Hackman and Lawler (1971) report that higher-order need strength moderates the relationship between job characteristics and job satisfaction; Atkinson (1964), that the relationship is moderated by degree of need for achievement; House (1972), that the relationship is moderated by the person's relative value priorities for intrinsic as compared with extrinsic rewards.

The more situationally determined personality characteristics such as motivations, expectations, perceptions, cognitions, and the like, are similarly not conceived or employed as direct causes of job satisfaction but as important moderators of the individual's response to his job and work environment. Ex- 
amples are common, particularly in the literature relating to employment selection, career choice, and performance motivation. In each of these areas the role of personality variables is usually that of determining what particular job facets offer satisfaction or dissatisfaction potential, rather than of determining directly the resultant level of satisfaction. The logic of employment selection, for example, includes the matching of the individual's "situational personality" to the reward potentials of the job in order to ensure satisfaction. Similarly, work motivation theories include the notion (with supporting evidence) that the generation and maintenance of motivationbehavior systems rest upon experiencing outcomes compatible with the individual's expectations, perceptions, and so on.

The relevance of this to understanding the causes of job satisfaction at the societal level (as compared with the individual level) lies in the presumption that individual personalities, far from being infinitely and randomly unique, display uniformities for large segments of the employed population to such a degree that generalizations concerning personalityenvironment interactions are strong and valid even though imperfect.

\section{ABILITIES}

There are very few reports on the role of individual abilities in the causation of job satisfaction. It is known from many studies of employment selection, however, that abilities known to be valid predictors of subsequent job performance often predict also to direct measures of job satisfaction or to behaviors (e.g., early voluntary quitting) that can be presumed to reflect job dissatisfaction. Furthermore, it is well established that self-report of a discrepancy between the abilities possessed and the abilities required by one's job is a strong and prevalent correlate of job satisfaction. 


\section{TRANSIENT PERSONALITY TRAITS}

Short-term fluctuations in job satisfaction-for example, over periods measured in hours or days-have been largely ignored, except for the pioneering study of Hersey (1955). His report suggests that cyclical, transitory moods associated with on-job or off-job events are associated with job satisfaction. Unless it is shown that some jobs and job environments induce large, frequent, or prolonged transient states of dissatisfaction, such transient personality influences are probably of little interest in the context of social indicators.

\section{PERSON-ENVIRONMENT INTERACTIONS}

While many environmental variables have displayed a direct relationship to job satisfaction, only a few such direct relationships have been reported with respect to the "person" variables. This is in accord with common sense: by definition job satisfaction is satisfaction with or about something experienced as "environment," for which there is some objective or commonly perceived reality. The role of person variables in the causation of job satisfaction or dissatisfaction is virtually always that of moderating the association between the environment and the satisfaction response. This observation, however, does not imply a minor role for the person variables; on the contrary, the major portion of the variance in job satisfaction appears to be unaccountable from environmental considerations alone.

\section{OBJECTIVE AND SUBJECTIVE WORK ENVIRONMENTS}

The distinction between objective and subjective work environments is significant. Studies employing both kinds of measurements of the work environment generally agree that subjective measures correlate with satisfaction more strongly than do objective measurements. It is tempting to think that the subjective measures are merely contaminated or biased in such a way as to produce spuriously elevated correlations with job 
satisfaction. However, it is equally plausible that the objective measures applied to a work group, an organization, or some other defined population are at best an error-laden, crude average of the objective realities and that the objective conditions are not the same for all similarly classified persons. Further, regardless of measurement problems and the definition of "objectivity," the practical problems of developing and using social indicators must treat subjective environments if indeed it is the perceived environment that the person responds to. Ancient philosophical issues aside, the empirical evidence suggests that objective measures and subjective measures are in some way different and complementary in their significances, not merely different in degree of validity (e.g., French and Caplan, 1972).

\section{LEVEL OF ANALYSIS}

The distinction must be maintained between the causes of job satisfaction that operate at and are detectable at the individual level, and those that operate at and are detectable at the level of collectivities. Virtually all of the empirical inquiry and the theoretical models employed so far are at the individual level--even though societal implications are often inferred. Satisfaction is treated as a psychological phenomenon and aggregations are treated only as representations for populations of the prevalence of such individual-level phenomena. No one so far as we know has addressed the analogous issues of how a collectivity might be deemed to be "satisfied" with its occupational system, its work activity system, and its allocation of persons to work roles. We leave the reader to press forward on these issues, and only maintain that sociological phenomena are not necessarily isomorphic with psychological phenomena.

\section{CONSEQUENCES OF JOB SATISFACTION}

In sharp contrast to the voluminous and diverse literature on the causes of job satisfaction, in which satisfaction is treated as 
an outcome of antecedent environmental and personal factors, there is very little theory and empirical data about the consequences of which job satisfaction is regarded as a causal antecedent.

Figure 1 imposes a distinction among the consequents that are most usefully assessed at the individual level, at the organization or institutional level, and at the societal level. The rather arbitrary allocation of examples to each category is based not on the inherent or sole reference of the named outcome but rather upon the more common, or more probable, use of the outcome in predictive and interpretive models. For example, the association between job satisfaction and self-narcotization (Mangione and Quinn, 1973) can have meaning for those concerned with individual welfare, employing organizations where alcoholism or other drug abuse is a problem, and the society as a whole which might be impaired. We would choose, in this case, to regard the outcome as primarily of interest in the context of individual welfare.

The basic proposition on which rest the correlations between job satisfaction and the several outcomes is the following: the experience of dissatisfaction, much like the experience of pain or hunger, initiates psychobiological responses in the individual that may, with some probability, serve to remove or mitigate the dissatisfaction. Thus, job dissatisfaction is in the normal case a transitional or temporary state which prompts some sort of accommodative or adaptive behavior, and in this limited sense is a partial "cause" of that behavior. In contrast, the experience of positive job satisfaction tends to perpetuate the psychobiological behaviors that induced, or are otherwise associated with, the experience of satisfaction. These individual accommodative processes become significant at the organizational or societal levels to the degree that they are prevalent and to the degree that they affect the integrity of the organization and/or society.

The Minnesota Studies in Vocational Rehabilitation (Lofquist and Dawes, 1972) identified two primary modes by which individuals adjust to their work situation, namely, an active 
mode in which the individual operates on his environment to make it better fit his personal characteristics, and a reactive mode in which the individual changes himself.

As a concrete example, consider a person dissatisfied with his pay who may accommodate by leaving his employer to join another offering higher pay. In the typical case, he may have restored his own satisfaction, done harm to his first employing organization, and perhaps sustained society's need to maintain some market fluidity and equity between economic contributions and economic rewards. Consider a rather different case in which a person dissatisfied with the routineness and low challenge of his job, but constrained from some preferred accommodative behavior, who moderates his dissatisfaction by distorting his perceptions of his own capabilities and own potential for work performance. In the typical case he will have done harm to himself in the long run, advantaged his employing organization as well as his own comfort in the short run, and reduced the adaptivity and work force competence of his society.

Figure 1 suggests a few of the more specific active and reactive accommodative strategies. Empirical evidence is lacking in scope and deficient in quality, but not entirely absent. A few representative examples are mentioned:

(1) Quinn et al. (1973) report job dissatisfaction to be significantly correlated with (1) life dissatisfaction, (2) low self-esteem, (3) depression, (4) psychosomatic illness symptoms, (5) work-related fatigue, and (6) participation in off-job recreational, political, and religious organizations-all of these measurements based upon self-reports. Significant correlations are also reported for outcomes independently measured such as (1) work-related injury and illness rates, and (2) supervisory ratings of productivity and quality of work performance. All of these correlations are relatively weak, although significant, and some apply differentially to subpopulations based on employment organization membership and demographic characteristics.

(2) Andrews and Withey (1974) report from a national sample of adults that job satisfaction has a significant role in overall life 
satisfaction even after removal of variance redundancy with other predictors.

(3) Ross and Zander (1957) and Mangione (1973) report significant correlations between measured job satisfaction and subsequent self-initiated job change, in longitudinal inquiries.

(4) A number of different investigators show absence rates to be correlated with job satisfaction, although not equally for all populations or work environments.

(5) Vroom (1964), among others, has summarized the literature concerning job satisfaction and productivity, with the conclusion that positive correlations occur frequently, negative correlations can and do occur, and the typical association is positive but weak.

(6) Sheppard and Herrick (1972) report associations between job dissatisfaction and extremist political voting behavior.

(7) French and Caplan (1972) report significant correlations between job dissatisfaction and an index of physiological heart disease risk factors.

(8) Mangione and Quinn (1973) report correlations between job dissatisfaction and (1) work-related use of self-narcotizing drugs, and (2) an index of on-job destructive behaviors including theft, sabotage, and the like.

The foregoing roster of examples could be extended, but not very much. The exploration of the correlations between job satisfaction and the various individually or socially valued consequences has hardly begun. The evidence so far suggests that these correlations will be large in number, small in magnitude. That is, a wide range of outcomes will be shown to be associated with job satisfaction, but job satisfaction will appear as a sole or even as a major causal factor in only a few cases, if any. The importance of job satisfaction in the context of the quality of employment will rest on the pervasiveness of its correlations rather than on any singular diagnostic or predictive power in limited interpretive models. The "true" significance of job satisfaction (as of all other commonly used and preferred social indicators) is to be discerned only when the causes and the consequents are treated in complex multivariate 
models in which there are provisions for alternative and contingent, as compared with unitary and discrete, consequences. Thus, job satisfaction would be expected to show a significant relationship to individually and socially valued consequences taken as a set, but not necessarily with any one particular consequence.

\section{DEVELOPMENT PRIORITIES}

At the present time, aggregated measures of job satisfaction have rather limited utility as indicators of employment quality at the level of societal trends, at the level of comparisons among segments of the work force, and at the level of comparisons among classes of jobs and occupations. This observation applies equally to many other potential social indicators, both "hard" and "soft," and does not imply that there is something uniquely or more strongly disabling in the case of job satisfaction compared with other measures. The available information base about the causal and consequential correlates of job satisfaction, while complex and frustrating to interpret, includes regularities and some strong associations that compel further effort to improve the utility of the concept and the measures.

In this section we mention briefly some themes and guidelines that we feel should be given priority in the next years.

\section{MAPPING THE CORRELATES OF SATISFACTION}

Progress toward a more dependable and more richly detailed representation of the correlates of job satisfaction is likely to be slow and wasteful if we continue to rely, as we have, on studies of small, opportunistic, unique populations, work environments with a limited range of measured variables, and primitive models for analy sis that rely much on the bivariate hypothesis-testing mode of inquiry. Not all past studies, of course, are so limited, but most of them are. The preceding section of this paper 
provides some examples of tantalizing relationships that cannot confidently be generalized because associated variables remain untreated and thus alternative interpretations remain equally plausible. However, merely to recommend big study designs is insufficient unless such studies can be carried out in ways that exploit advanced multivariate analytic methods, utilize more complex theories to guide analysis, and generate causal models that lend themselves to experimental validation and to validation in longitudinal studies.

It should be assumed that mapping correlates of satisfaction involves not only the identification and size estimation of correlations, but also the definition of relevant interactions, substitutions, and contingencies. Inquiries that exclude such considerations will contribute little but further complexity; studies that include such considerations may serve to simplify and clarify. For example, inspection of several hundreds of available empirical first-order correlations between attributes of jobs and satisfaction of job occupants (Block D of Figure 1) would suggest that the roster of relevant job descriptors is very large and virtually unlimited, that the obtained correlations are variable in size and occasionally in sign for different test populations, and that there is no apparent simple structure in the set of correlations. One is tempted to conclude that the associations are, in general, so weak (e.g., rate of pay and job satisfaction, r. $=.20$ ), so numerous, and so inconstant that simple generalizations are not plausible. However, it seems likely that this particular bucket of worms may be made tractable. One recent analysis (Barnowe et al., 1973) found that a rather short roster of job descriptors, treated not separately but as an additive set (there were not significant interactions among them), generated a highly significant association with job satisfaction. The associations were of a magnitude that may exhaust the variance in satisfaction that is explainable from the attributes of the job itself and the micro-environment of the job. In short, confusion from many variables and small correlations arises from the noise of removable redundancy-but the redundancy must be discovered. 
A parallel example is to be seen in the relationships between job satisfaction and individual responses (Block $L$ of Figure 1). The correlations found in this domain are characteristically small and not always reliably replicated in different populations. It seems plausible, however, that such a domain of variables descriptive of individual adaptive and coping behaviors may be shown to have relatively simple and interpretable properties as a set, if the set is defined in terms of the additivity or mutual exclusivity of the components of the set. For example, job dissatisfaction has a consistent, but weak association with withdrawal by quitting the job and with protective perceptual distortion, but it may be rather strongly associated with these two variables if they are treated jointly as alternative responses. This has not yet been subjected to study as far as we know.

As these examples suggest, a style and scale of inquiry that precludes the systematic treatment of interactions, contingencies, intactness of variable sets, "fit" phenomena, and redundant causation are not the type of inquiry likely to advance our mapping of the correlates of job satisfaction, nor is it likely to stimulate appropriately enlarged theoretical models for validation and interpretation.

\section{IMPROVED MODELS, THEORIES}

The correlational mapping of the phenomena under discussion must proceed through interactive theoretical and empirical work. The theoretical approaches and models employed so far have been relatively restricted in scope. They have been almost exclusively psychological in nature and often have rested on dubious or ambiguous assumptions. Next stages of development will require models which, while necessarily still incomplete, will be enlarged over existing models, so that they have causal implications, treat multiple causes and consequences, draw upon concepts and variables from several of the variable classes suggested in Figure 1, and provide linkages to established theoretical systems of sociology and economics as well as those of psychology. 
There are a few examples available of theoretical efforts displaying some or all of these properties. One example is that of Lawler (1973: 75) who proposes a causal model of the determinants of job satisfaction. His suggested model provides for initiatory causal forces from both personal and environmental sources, employs motivational assumptions, employs considerations of individual values and individualistic perceptual processes, as well as equity evaluation processes, and makes assumptions about the effects of different forms of resultant inequity. Mainly psychological in its roots, it is a model designed for application to individual phenomena. Analogous modeling is needed to treat job satisfaction at higher levels of aggregation and social interpretation.

\section{TIME AND DELAYED CONSEQUENCES}

Including job satisfaction in a model of the quality of employment in the context of social indicators implies a concern for societal change and for the prediction of future conditions that might warrant advance preventive or ameliorative action. Effective use of job satisfaction measures in such a context requires particular attention to causal chains and to deferred consequences of current conditions. Nearly all past and current inquiry about job satisfaction involves correlational analysis of cross-section or one-time measurements. While causal imputations are not precluded and reference may be made in any case to some nonsurvey historical or subsequential records, it remains that few studies have been done that are experimental in nature, employ time-series data, or consider consequences that may take months or years to unfold. High priority should be given to longitudinal studies, to the accumulation of time-series data archives, and to the validation of causal propositions by experiment.

\section{TRANSPARENCY}

In all of the prevailing methods for measuring job satisfaction with a view toward aggregation, purpose is transparent to the 
respondents. Measures, therefore, are potentially distorted by purposeful intent or such unconscious influences as may operate when the measurement process is wholly within the respondents' control. There is so far little evidence to support the notion that socially desirable responses are given with undue frequency by individuals with a high need for social approval. However, there may still be pervasive effects associated with other attributes of the individual (status, sex, and so forth) that distort the measurements or that add some favorable (or unfavorable) constant to the measures. Also, it can be anticipated that job satisfaction responses may sometimes be the target of persuasive or collusive efforts. It would be useful to have some ingenious experiments and field tests to see how resistant job satisfaction measures are to intentional or circumstantial influence, and if necessary to begin development of less malleable instruments.

\section{THE INDIFFERENTS AND AMBIVALENTS}

There are plausible speculations, and even some fragmentary evidence, that the prevailing measures of job satisfaction may fail to discriminate among individuals who are truly indifferent about the quality of their employment and individuals who are ambivalent in the sense of holding strongly discriminated positive and also negative opinions regarding their jobs. Inquiry is needed to ascertain whether such respondents exist in numbers sufficient to affect the utility of aggregated job satisfaction indicators, and indeed, whether trends in the proportion of indifferents may themselves be a useful social indicator.

\section{THE SOCIAL VALUE OF JOB DISSATISFACTION}

Most treatments of job satisfaction assign to positive satisfaction, either expressly or implicitly, the status of an ultimately valued end state. This notion is implicit in models and in data interpretations suggesting that job satisfaction should be maxi- 
mized, that job dissatisfaction is always undesirable, that the social reason for seeking to improve the quality of employment is to increase resultant satisfaction. This prevalent view is part of the baggage we inherit from the psychological and individualistic orientations from which job satisfaction research arose. From the perspective of the individual member of the work force such a view can be defended, but in the context of aggregated measures to represent the quality of employment for a population or a society a different view must be taken.

We strongly urge that job satisfaction be treated not only as a valued goal or end state, but also and primarily as a dynamic process occurring primarily as an individual phenomenon but having significant implications for societal adaptivity as well. In this view, becoming dissatisfied is an essential part of the motivations of individuals to alter themselves or their job environments in ways that serve personal, institutional, and societal purposes. This view is elaborated elsewhere (Seashore, 1973) so no more will be said here other than: (1) we should give at least as much emphasis to understanding the consequences of job dissatisfaction as we do to the causes, and (2) we should utilize theoretical models that treat satisfaction both as a desired state for the individual and also as a source of societal adaptivity.

\section{REFERENCES}

ANDREWS, F. and S. WITHEY (1974) "Developing measures of perceived life quality: results from several national surveys." Social Indicators Research 1.

ATKINSON, J. W. (1964) An Introduction to Motivation. Princeton: Von Nostrand, Reinhold.

BARNOWE, J. T., T. W. MANGIONE, and R. P. QUINN (1973) "Quality of employment indicators, occupational classifications, and demographic characteristics as predictors of job satisfactions," pp. 385-392 in R. P. Quinn and T. W. Mangione, The 1969-1970 Survey of Working Conditions: Chronicles of an Unfinished Enterprise. Ann Arbor: University of Michigan Survey Research Center.

CARZO, R., Jr. and J. N. YANOUZAS (1969) "Effects of tall and flat organizational structure." Administrative Sci. Q. 14: 178-191. 
COBB, W. L., Jr. and R. P. QUINN (1973) "Factor analyses of importance ratings of job facets," pp. 27-84 in R. P. Quinn and T. W. Mangione, The 1969-1970 Survey of Working Conditions: Chronicles of an Unfinished Enterprise. Ann Arbor: University of Michigan Institute for Social Research.

DUBIN, R. (1970) "Sources of attachment to work." (manuscript)

EMERY, R. E. and E. L. TRIST (1965) "The causal texture of organizational environments." Human Relations 18, 1: 21-31.

EVANS, M. G. (1969) "Conceptual and operational problems in the measurement of various aspects of job satisfaction." J. of Applied Psychology 53, 1: 93-101.

EWEN, R. B. (1967) "Weighting components of job satisfaction." J. of Applied Psychology 51, 1: 68-73.

FORM, W. H. (1973) "Auto workers and their machines: a study of work, factory, and job satisfaction in four countries." Social Forces 52,1 .

FRENCH, J.R.P., Jr. and R. D. CAPLAN (1972) "Organizational stress and individual strain," in A. J. Marrow (ed.) The Failure of Success. New York: AMACOM.

FRENCH, J.R.P., Jr., W, L. RODGERS, and S. COBB (for thcoming) "Adjustment as person-environment fit," in G. Coelho and D. Hamburg (eds.) Coping.

GEORGE, J. R. and L. K. BISHOP (1971) "Relationship of organizational structure and teacher personality characteristics to organizational climate." Administrative Sci. Q. (December): 467-475.

GHISELLI, E. E. and C. W. BROWN (1955) Personnel and Industrial Psychology. New York: McGraw-Hill.

HACKMAN, J. R. and E. E. LAWLER III (1971) "Employee reactions to job characteristics." J. of Applied Psychology Monograph 55: 259-286.

HERSEY, R. (1955) Zest for Work. New York: Harper.

HILL, P. (1973) Towards a New Philosophy of Management. London: Tavistock.

HOPPOCK, R. (1935) Job Satisfaction. New York: Harper.

HOUSE, J. S. (1972) "The relationship of intrinsic and extrinsic work motivations to occupational stress and coronary heart disease risk." Ph.D. dissertation. University of Michigan.

HULIN, C. L. and M. J. BLOOD (1968) "Job enlargement, individual differences, and worker responses." Psych. Bull. 69, 1: 41-55.

KENDALL, L. M. (1963) "Canonical analysis of job satisfaction and behavioral personal background, and situational data." Ph.D. dissertation. Cornell University.

LANDY, F. (1973) "Men at work." (manuscript)

LAWLER, E. E., III (1973) Motivation in Work Organizations. Monterey: Brooks/ Cole.

- (1969) "Job design and employee motivation." Personnel Psychology 22: 426-435.

LITWIN, G. H. and R. A. STRINGER, Jr. (1968) Motivation and Organizational Climate. Boston: Harvard University Graduate School of Business Administration, Division of Research.

LOCKE, E. A. (1969) "What is job satisfaction?" Organizational Behavior and Human Performance 4, 3: 309-336.

LOFQUIST, L. H. and R. V. DAWES (1972) "Application of the theory of work adjustment to rehabilitation and counseling." Minnesota Studies in Vocational Rehabilitation Bulletin 58. 
MANGIONE, T. W. (1973) "Validity of job satisfaction." Ph.D. dissertation. University of Michigan.

- - - and R. P. QUINN (1973) "Job satisfaction, counter productive behavior, and self-narcotizing withdrawal from work." Ann Arbor: Survey Research Center.

PORTER, L. W. and E. E. LAWLER III (1968) Managerial Attitudes and Performance. Homewood, Ill.: Richard Irwin.

QUINN, R. P., C. C. CAMMANN, N. GUPTA and T. A. BEEHR (1973) "Effectiveness in work roles." Final Report to the Manpower Administration, U.S. Department of Labor (Aprii). (unpublished)

QUINN, R. P. and W. L. COBB, Jr. (1971) "What workers want: fact or analyses of importance ratings of job facets." Ann Arbor: Survey Research Center.

QUINN, R. P. and T. W. MANGIONE (1973) The 1969-1970 Survey of Working Conditions: Chronicles of an Unfinished Enterprise. Report to the Department of Labor.

- (1973) "Evaluating weighted models of job satisfaction: a Cinderella story," pp. 85-114 in R. P. Quinn and T. W. Mangione, The 1969-1970 Survey of Working Conditions: Chronicles of an Unfinished Enterprise. Ann Arbor: Institute for Social Research.

QUINN, R. P. and L. J. SHEPARD (1974) The 1972-73 Quality of Employment Survey. Ann Arbor, Michigan: Survey Research Center.

RONAN, W. W. (1970) "Individual and situational variables relating to job satisfaction." J. of Applied Psychology Monograph 54, 1: 1-31.

--- and E. MARKS (1973) "The structure and stability of various job satisfaction measures." Studies in Personnel Psychology 6, 1: 2-27.

ROSS, J. T. and A. ZANDER (1957) "Need satisfaction and employee turnover." Personnel Psychology 10: 327-338.

SCHWARTZ, A. P., W. W. RONAN, and C. J. DAY (1974) "Individual differences and job satisfaction." (manuscript)

Science Research Associates (1973) SRA Attitude Survey. Chicago.

SEASHORE, S. E. (1973) "Job satisfaction as an indicator of quality of employment." Prepared for the Symposium on Social Indicators of the Quality of Working Life, Canada Department of Labor.

SHEPPARD, H. and N. J. HERRICK (1972) Where Have All the Robots Gone? New York: Free Press.

SMITH, P. C., L. M. KENDALL, and C. L. HULIN (1969) The Measurement of Satisfaction in Work Retirement. Chicago: Rand McNally.

VROOM, V. H. (1964) Work and Motivation. New York: John Wiley.

WANOUS, J. P. and E. E. LAWLER III (1972) Measurement and meaning of job satisfaction." J. of Applied Psychology 56, 2: 95-105.

W. E. Upjohn Institute for Employment Research (1973) Work in America: Report of a Special T'ask Force to the Secretary of Health, Education, and Welfare. Cambridge: MIT Press. 